\title{
ALEITAMENTO MATERNO E PARENTALIDADE: UMA RELAÇÃO EM CONSTRUÇÃO
}

\author{
BREASTFEEDING AND PARENTALITY: A RELATIONSHIP UNDER CONSTRUCTION
}

\author{
Elisangela Ribeiro da Silva ${ }^{1}$ \\ Edegar Fronza ${ }^{2}$ \\ Márcia Rejane Strapasson ${ }^{3}$
}

RESUMO: Objetivo: conhecer como se dá a construção que compreende as relações entre paternidade e aleitamento materno. Método: trata-se de um estudo qualitativo, exploratório e descritivo, com is pais que tinham filhos de até dois anos de idade, em aleitamento materno, acompanhados em consulta de puericultura em Unidade Básica de Saúde. Foram excluídos pais com diagnóstico de doença mental, aqueles cujos filhos tinham contraindicação absoluta para o aleitamento materno ou que as mães conviviam com o vírus do HIV. O recorte temporal abrangido foi de março a julho de 2019. A coleta de dados ocorreu por meio de entrevista semiestruturada. Para a análise dos dados, utilizou-se a Técnica Análise de Conteúdo do tipo Temática. Resultados: Emergiram três categorias centrais: inserção paterna no processo da amamentação; dificuldades paternas na participação do processo de amamentação; questões de gênero e realização da paternidade. Considerações Finais: os pais reconhecem os benefícios do aleitamento materno no desenvolvimento e crescimento dos filhos e procuram participar deste processo. Novas discussões e investigações são necessárias para esclarecer as nuances que permeiam esta inserção e seus significados.

Palavras- chave: Aleitamento materno. Lactação. Recém-nascido. Paternidade.

ABSTRACT: Objective: To know how the construction that comprises the relationship between paternity and breastfeeding takes place. Method: This is a qualitative, exploratory and descriptive study with is parents who had children under two years of age that were being breastfed and were also being cared for in a Health Center. Those who did not meet the inclusion criteria were excluded: parents diagnosed with mental illness, those whose children had absolute contraindications to breastfeeding or who mothers were HIV

\footnotetext{
I Enfermeira especialista em Atenção Básica pelo Programa de Residência Multiprofissional da Universidade do Vale do Rio dos Sinos - UNISINOS, São Leopoldo, RS, Brasil.

2 Biólogo, e Doutor em Biotecnologia pela Universidade de Caxias do Sul - UCS. Docente da Área de Conhecimento de Ciências da Vida da Universidade de Caxias do Sul, RS, Brasil. Mestre em Biociências pela Pontifícia Universidade Católica do Rio Grande do Sul - PUCRS. E-mail: efronza@ucs.br.

3 Enfermeira, Especialista em Enfermagem Obstétrica pela Universidade do Vale do Rio dos Sinos UNISINOS. MBA em Gestão de Negócios de Saúde pela UNISINOS. Mestre em Enfermagem pela Universidade Federal do Rio Grande do Sul - UFRGS e Doutora em Ciências da Saúde: Ginecologia e Obstetrícia, também pela UFRGS. Docente no curso de Graduação em Enfermagem da UNISINOS.
} 
positive. The time frame covered was from March to July 2019. Data collection occurred through semi-structured interviews. The Thematic Content Analysis Technique was used for data analysis. Results: from the data analysis three central categories emerged: paternal insertion in the breastfeeding process; paternal difficulties in participating in the breastfeeding process; gender issues and paternity. Final considerations: it was established that parents know the benefits of breastfeeding in the development and healthy growth of their children and are willing to participate in this process.

Keyword: Breastfeeding. Lactation. Newborn. Paternity.

\section{INTRODUÇÃO}

O período que compreende os primeiros mil dias de vida, incluindo a concepção, os 280 dias da gestação e os 730 dias dos primeiros dois anos de idade é intitulado "janela de oportunidades". Este recorte temporal é concebido como momento oportuno para implementar estratégias que assegurem cuidados adequados a gestante, nutriz e ao lactente, uma vez que é nos primeiros mil dias que pode ocorrer danos à saúde futura da criança (ANDRADE et al., 2oi6).

O leite materno (LM) é considerado o alimento mais adequado para o desenvolvimento do lactente, além de ser uma maneira segura, eficaz e econômica para a nutrição da criança. Assegura oferta essencial de nutrientes e hidratação, não necessitando de nenhum outro alimento até o sexto mês de vida, além de oferecer proteção imunológica e desenvolvimento físico, mental, psicológico e emocional adequados (OLIVEIRA, LIMA, 2015). Apesar de os benefícios do LM estarem bem estabelecidos, mundialmente apenas $40 \%$ dos lactentes com menos de 6 meses são amamentados exclusivamente (WABA, 2019), sendo que nos países de baixa e média renda, esse percentual é de apenas $37 \%$. A Assembleia Mundial da Saúde estabeleceu como meta para 2025 "aumentar a taxa de amamentação exclusiva para pelo menos 50\%" (VICTORA et al., 2016).

Neste contexto, a inserção paterna vem sendo amplamente incentivada, discutida e problematizada. No entanto, a figura do pai ainda vem marcada pela responsabilidade de prover a família de suas necessidades materiais, sendo a parentalidade denotada pelo estereótipo masculino que determina figuras de identidade próprias. Contudo na sociedade contemporânea, a paternidade torna-se excêntrica devido ao papel que culturalmente assumiu como responsável pelo sustento familiar, e por apresentar agora novas funções, como as de companheiro, cuidador, protetor, entre outras (RÊGO et al., 2016). Como 
evidenciado por Drago e Menandro (2014), ao fenômeno da paternidade também se inclui a maternidade, visto que esses dois protagonistas podem ser considerados partícipes de todo o processo de cuidado e formação do filho. Convergindo com essas afirmativas, estudo de Wallenborn, Chambers, Masho, (2014) realizado nos Estados Unidos, denota que o apoio paterno influencia diretamente nos resultados da prática e no tempo de amamentação. Reforça que mães que recebem pouco apoio paterno pós-parto apresentam menor probabilidade para iniciar e manter a amamentação.

O presente estudo remete à relação do pai no processo de amamentação, na perspectiva de apresentar a figura paterna como partícipe desse processo, tirando da mãe a total responsabilidade pelo sucesso da amamentação de seu filho. Denota-se a importância de esclarecer o quanto a participação do pai pode contribuir para o sucesso da prática da amamentação, evitando dessa forma o desmame precoce. Assim, a motivação para o desenvolvimento deste estudo externou-se a partir do contato com mães e lactentes que retornam à unidade básica de saúde para consultas de puericultura e relatam encontrar dificuldade em amamentar exclusivamente o lactente. A maioria delas apresentam histórias semelhantes, pautadas na ausência de uma rede de apoio ou da participação paterna nesse processo. A prática de alimentação de seus filhos é influenciada pela cultura e por crenças familiares que na sua maioria têm o hábito de introduzir outros leites e outros líquidos ou sólidos como complemento alimentar. Esses relatos são constantes na consulta puerperal e de puericultura, causando imensa inquietação, e tornando-se, objeto de investigação.

Este estudo poderá contribuir com a comunidade científica para o conhecimento de como se estabelece a relação entre a paternidade e a prática da amamentação, além de incentivar a participação paterna neste processo, visando à promoção e à proteção do AM e contribuindo na redução do desmame precoce.

Buscando responder a essas indagações, este estudo tem a seguinte questão de pesquisa: Como se estabelece a construção da relação entre paternidade e AM?

Para tal, tem-se como objetivo geral, conhecer como se dá a construção que compreende as relações entre paternidade e AM. 


\section{MÉTODO}

Trata-se de um estudo qualitativo, que tem caráter exploratório e descritivo, realizado com pais que tinham filhos em AM, acompanhados nas consultas de puericultura.

Participaram do estudo pais que tinham filhos de até dois anos de idade, em AM, e que estavam sendo acompanhados em consulta de puericultura em uma Unidade Básica da região metropolitana de Porto Alegre, no Estado do Rio Grande do Sul. Esses pais eram maiores de 18 anos e aceitaram participar do estudo após assinatura do termo de consentimento. $\mathrm{O}$ recorte temporal abrangido foi de março a julho de 2019. Foram excluídos pais com diagnóstico de doença mental, aqueles cujos filhos tinham contraindicação absoluta para o AM ou cujas mães conviviam com o Vírus do HIV.

Para a definição do número de entrevistas, seguiu-se o conceito de Gaskell (2013), o qual afirma que, para pesquisas que utilizam a entrevista como estratégia de coleta de dados, o número situa-se entre 15 a 25 entrevistas. A seleção dos participantes do estudo ocorreu através da relação de crianças em consultas de puericultura, após contato realizado pelo Agente Comunitário de Saúde e por telefone. Esses pais foram convidados a comparecer na unidade de saúde ou aceitaram receber a pesquisadora no domicílio.

A coleta de dados ocorreu por meio de entrevista semiestruturada, contendo três questões norteadoras sobre a percepção paterna quanto a: I) sua participação no processo de amamentação de seu filho; 2) significado paterno frente a sua inserção nesta prática; 3) principais dificuldades encontradas e ações desenvolvidas no cotidiano da amamentação para auxiliar na prática.

A entrevista ocorreu com data e horário agendado e sala reservada, considerando a disponibilidade dos participantes e respeitando sua privacidade. A maioria das entrevistas foi realizada em visita domiciliar, de acordo com as escolhas e melhor conforto dos entrevistados. As entrevistas foram gravadas com uso de aparelho digital, mediante autorização dos participantes, sendo transcritas em sua totalidade. Após a transcrição, o áudio foi destruído, ficando os registros sob a guarda da pesquisadora. Os nomes dos participantes foram substituídos pela letra $\mathrm{P}$ de pai, mantendo-se o sigilo e anonimato dos participantes. A coleta dos dados ocorreu no período de junho a agosto de 2019. 
Para validar as questões do instrumento de coleta, um teste piloto foi realizado pela pesquisadora junto a dois sujeitos não elegíveis para o estudo, visando à adaptação e às melhorias do instrumento.

Para a análise dos dados, utilizou-se a Técnica Análise de Conteúdo do tipo Temática, conforme Minayo (2014), que contempla a pré-análise, exploração do material e a interpretação de resultados.

Para este estudo foram consideradas as questões éticas, conforme a Resolução Ministerial no 466/2012, que trata da pesquisa em seres humanos (BRASIL, 2012). A pesquisa foi realizada após a aprovação deste projeto pelo Comitê de Ética e Pesquisa (CEP) da Universidade do Vale do Rio dos Sinos - UNISINOS, sob parecer de número 043198/2019 e CAAE: 12321219.2.0000.5344.

\section{RESULTADOS}

Participaram do estudo is pais que tinham filhos de até dois anos de idade, em AM, e que estavam sendo acompanhados em consulta de puericultura na Unidade Básica de Saúde. Os participantes apresentaram idade entre 19 e 46 anos e a maioria possuia ensino médio completo.

Após a análise dos dados, emergiram três categorias centrais que compuseram o corpus de discussão dessa investigação, a saber: I) inserção paterna no processo da amamentação, 2) dificuldades paternas na participação do processo de amamentação e 3) questões de gênero e realização da paternidade.

\section{INSERÇÃO PATERNA NO PROCESSO DE AMAMENTAÇÃO}

Alguns pais fizeram menção à prática da amamentação como um processo biológico materno, no entanto salientaram que sua participação pode se dar de outras formas, como informado por Pr e P4:

“Eu não tenho a mama, mas eu faço tantas outras coisas...”. (PI).

"Estou sempre presente em casa, a parte de amamentar é dela porque tem a mama, mas eu cuido de todo resto, para ela ter esse tempo [...]”. ( $\left.\mathrm{P}_{4}\right)$.

As falas a seguir mostram que a participação paterna supera o apoio emocional e a realização de tarefas do cotidiano familiar. Este pode auxiliar inclusive na técnica e posicionamento correto do bebê, visando à qualificação do processo de amamentação. 
“Tenho que apoiar ela [mãe], dar força. No início o bebê teve dificuldade na pega da mama, mas eu sempre auxiliei, acalmava ele [recém-nascido]”. (P6).

"Quando ela [mãe] está com dor, eu ajudo a tirar o leite, eu faço massagem na mama”. ( $\left.\mathrm{P}_{13}\right)$.

Para alguns pais, a participação no AM dos filhos é uma maneira de se envolver nos cuidados, pois relataram que assim conseguem desenvolver seu papel nos primeiros dias de vida dos bebês e se sentem notáveis nesse processo, como mencionado por $\mathrm{P}_{7}$ P $\mathrm{P}_{13}$.

"É bom ver o crescimento e o desenvolvimento da minha filha, estar ali fazendo parte de tudo, me sinto importante para ela [filha]". $\left(\mathrm{P}_{7}\right)$.

"Estou acompanhando o meu filho, todo processo que ele [filho] está passando de crescimento e desenvolvimento, sabe, estou fazendo parte dessa construção [...]”. ( $\left.\mathrm{P}_{13}\right)$.

$\mathrm{P}_{3}$ mostra-se partícipe do processo de amamentação de seu filho, contribuindo para que esta prática fosse estabelecida, buscando proporcionar tranquilidade e conforto a mulher. Esse fato pode contribuir, em parte, para a produção láctea, como relatado:

“Que se eu não a ajudasse [mãe], não teria tanto entusiasmo e disposição para amamentar, se sentiria cansada, e podia não produzir mais leite, não levaria a amamentação mais do que seis meses, o que seria muito ruim para o bebê, porque perderia as vitaminas do LM". $\left(\mathrm{P}_{3}\right)$.

$\mathrm{O}$ discurso de P8 permite inferir que o homem conhece os benefícios do AM, não somente para a criança como também para a mulher que amamenta, e se mostra reconhecedor de que sua participação influencia este processo.

"Eu vejo que é bom para recuperação dela [mulher], vai ser uma recuperação mais rápida. Se eu a ajudo [mulher] não vai fazer muito esforço, eu me levanto e faço o que eu posso fazer por ela [mulher]". (P8).

Alguns pais salientaram os inúmeros benefícios da amamentação para a saúde do lactente, como a redução de infecções, adequado crescimento e desenvolvimento cognitivo, conforme as falas:

"Muitos benefícios de saúde, evitando infecções e gripes, eu li em vários lugares, inclusive na carteirinha de vacinas, tem muita coisa boa sobre o LM”. ( $\left.\mathrm{PI}_{1}\right)$.

"O benefício do AM oferece tudo que ela [bebê] precisa: saúde, crescimento, boa energia. É a proteção dela [bebê], porque até na escola isso vai refletir [...]”. (PII).

"Saúde da criança, evita problemas, é uma proteção, ela [bebê] fica menos doente $[\ldots] ”$... (P15).

Ações de apoio e corresponsabilidade com tarefas diversas do cotidiano definem a contribuição do pai no processo de amamentação dos filhos. Quanto às atividades e cuidados diários com os lactentes, alguns pais declaram que se inserem nesse processo através da 
realização de tarefas domésticas. Sua inserção nesse processo lhes possibilita sentirem-se importantes e responsáveis pelo $\mathrm{AM}$ dos filhos, como relatam $\mathrm{P}_{4}$ e $\mathrm{P}_{5}$ :

"Eu faço coisas que eu não sei se ajuda, eu tento ajudar com as tarefas de casa que ela [mulher] estaria fazendo se tivesse tempo. Então eu fico responsável para ela [mulher] poder sentar-se e amamentar o neném. Cuido da roupa, da comida, da casa, faço o que ela [mulher] estaria fazendo quando ele [bebê] chora para mamar, ou quando ela [mulher] está cansada". $\left(\mathrm{P}_{4}\right)$.

"Os serviços de casa no geral, o banho das outras crianças, tudo que eu consigo fazer para ajudar ela [mulher], levar as crianças na escola, varrer o chão, lavar a louça que está na pia”. ( $\left.P_{5}\right)$.

Os pais entrevistados não se mostraram habilitados nos serviços domésticos, mas todos mencionaram suas diferentes implicações. Para Pr a limpeza de casa não é o que ele faz de melhor, mas não hesita em ajudar sua esposa e proporcionar a ela tempo para amamentar e se dedicar aos cuidados da criança.

"Eu me dedico em fazer a janta e o almoço para ajudar, não sou muito bom na limpeza, ajudo com a outra filha, arrumo e levo para o colégio, ajudo com o tema e assim vou dando tempo para mãe amamentar [...]”. (PI).

\section{DIFICULDADES PATERNAS NA PARTICIPAÇÃO DO PROCESSO DE AMAMENTAÇÃO}

O entrevistado Pi relata que, mesmo se fazendo presente no contexto familiar, vem apresentando algumas dificuldades de inserção, principalmente no que diz respeito a assumir questões educativas da outra filha, estar ciente e resolver assuntos que segundo ele se fazem necessários para que sua esposa esteja disponível e confortável para amamentar a criança.

\footnotetext{
"Talvez eu tenho um pouco de dificuldade porque tenho de ser mais responsável pela educação da filha maior nesse momento, em questão de impor regras e limites, ela está na pré-adolescência. Preciso cuidar disso não posso deixar minha esposa se preocupar, ela [mulher] precisa ficar tranquila". ( $\mathrm{PI}_{\mathrm{I}}$.

Mesmo reconhecendo a importância do apoio materno no processo da amamentação,
} os pais se sentem pressionados com o papel de provedores do sustento da família, o que muitas vezes determina sua ausência por alguns períodos do convívio familiar. Os entrevistados $\mathrm{P}_{2}$ e $\mathrm{P}_{5}$ relatam a necessidade de se ausentar por alguns dias de casa devido ao trabalho autônomo e entendem essa situação como uma dificuldade na participação do processo da amamentação:

\footnotetext{
"Eu fico um pouco ausente, como sou ambulante, sempre viajo para buscar mercadoria e fico uma semana fora”. $\left(\mathrm{P}_{2}\right)$.
} 
"Quando estou no serviço, passo pouco tempo em casa, assim não ajudo. Eu não estou todos os dias de corpo presente ou em todos os momentos”. ( $\left.\mathrm{P}_{5}\right)$.

A falta de experiência nos cuidados com o recém-nascido e de como agir frente às dificuldades com a amamentação reduz a participação paterna no envolvimento das tarefas de cuidado de seus filhos, como relatam $\mathrm{P}_{3}$ e $\mathrm{P}_{9}$.

“Às vezes não sei o que fazer quando ele vai mamar e começa a chorar, mas é falta de experiência”. $\left(\mathrm{P}_{3}\right)$.

"Quando ela [esposa] ainda estava no hospital, que não estava tendo a descida do leite, eu não sabia como ajudar. Cheguei a comprar um leite, mas logo em seguida começou a descer o lm”. (p9).

\section{QUESTÕES DE GÊNERO E A REALIZAÇÃO DA PATERNIDADE}

Para $\mathrm{P}_{3}$ a participação no processo de amamentação e cuidados com seu filho ultrapassa as tarefas desenvolvidas diariamente, pois antes mesmo de se constituir pai, responsável por sua família, já mobilizava sonhos e desejos relacionados a paternidade e suas atribuições.

\footnotetext{
"Eu sempre quis ter um filho, sonhava com isso. Quando ele [bebê] estava para chegar eu estava em uma situação bem crítica, tinha perdido o meu serviço. Minha esposa me falou e ficou esperando minha reação para saber se eu iria ficar feliz ou triste. Ainda assim, eu abri um sorrisão, ficando muito feliz, então é um prazer fazer parte disso tudo". $\left(\mathrm{P}_{3}\right)$.
}

A oportunidade de participação paterna no processo de amamentação dos filhos se torna prazerosa, fazendo desse envolvimento uma oportunidade de estar junto da família. $\mathrm{O}$ relato de Pıo evidencia o sentimento de gratidão e realização por estar fazendo parte do cuidado de seu filho e assim contribuir no processo de amamentação do bebê.
"Para mim é tudo, é muito legal, e a criança se acostuma com a gente. Isso é muito importante, eu estou sempre junto com a minha esposa e fico muito próximo do neném, sinto que posso fazer por ele [bebê], e pela minha família. É muito bom estar perto, os benefícios para mim são ıоo\%”. (Pıo).

Entretanto, para alguns pais, a realização das tarefas domésticas e a assistência nos cuidados com os filhos são vistos como função materna, e quando percebem a necessidade de ajudar, sentem-se envergonhados de se expressar, como explicam $\mathrm{P}_{2}$ e Piz.

"Não sei se é preciso falar dos serviços domésticos, fico sem graça, mas é o que faço às vezes, acho que não precisa ficar falando que faço, né, e cuido dele [bebê] quando a mulher não está em casa”. ( $\left.\mathrm{P}_{2}\right)$.

"Minha dificuldade é quando tem mais pessoas em casa, eu fico com vergonha quando as pessoas ficam olhando eu ajudar nos cuidados com a criança e da casa". (P12). 


\section{DISCUSSÃO}

Os resultados que emergiram da análise de dados apresentam o fortalecimento do vínculo e a constante construção da relação entre a paternid ade e a prática da amamentação. O presente estudo exibe a valorização da participação paterna no processo de amamentação do lactente. Apesar de biologicamente, o homem não poder amamentar, percebe que tem outras maneiras para participar, beneficiando a tríade mãe/bebê/pai e a prática de AM.

Neste sentido, na contemporaneidade, a participação dos homens no cotidiano familiar vem construindo uma concepção de nova parentalidade. Esta relação inclui maior participação nos cuidados de seus filhos, nutrição além do acompanhamento do crescimento e desenvolvimento em todas as etapas da vida. A responsabilidade pelo cuidar, ocupar-se, permitir-se e ser ocupado pelo filho, representa um retorno às questões da humanização do cuidado, contribuindo para a desconstrução da figura do antigo pai tradicional e provedor (JENERAL et al., 2015).

Neste cenário, identificou-se que alguns dos pais reconhecem a importância da prática do $\mathrm{AM}$ e seus benefícios tanto para o recém-nascido como para a mulher e a sociedade, e se mostram comprometidos com o processo. Frente a esses achados, estudo de Setúbal (2017) refere que a amamentação potencializa o retorno do útero à situação prégravídica e reduz consideravelmente os lóquios no pós-parto. Além disso, pode contribuir na redução de riscos para o desenvolvimento de câncer de mama, ovário, doenças cardiovasculares, entre outras.

Ainda, estudo conduzido por Victora et al., (2016), em Pelotas/RS, mostra que o LM transmite ao lactente elementos da microbiota e respostas imunes da mãe, e ainda fornece probióticos específicos para auxiliar o crescimento de bactérias benéficas. Ainda, o LM é uma fonte rica em vitaminas e ferro, protegendo contra doenças infecciosas, gastrintestinais, respiratórias, alérgicas e cardiovasculares, além de promover um adequado crescimento e desenvolvimento cognitivo e motor infantil (MARANHÃO et al., 2015). Uma coorte denotada por Victora et al., (2015) associa a amamentação com melhor desempenho em testes de inteligência, consequentemente maior nível de escolaridade e renda na vida adulta.

Corroborando com as premissas citadas anteriormente, os achados desta investigação mostraram que a participação paterna avança para além do apoio nas tarefas cotidianas. Os pais percebem sua importância no incentivo e proteção da amamentação, quando se 
mostram preocupados em auxiliar no posicionamento correto do recém-nascido e na técnica adequada para a amamentação. Estudo denotado por Lima, Cazola e Picoli (2017) reforça a importância da participação e apoio do pai nos primeiros dias de puerpério para o estabelecimento e manutenção da amamentação exclusiva. No período de pós-parto imediato, podem surgir dificuldades na amamentação, como fissuras, ingurgitamento mamário, mastite, interferência dos familiares e outras situações que podem contribuir para o desmame precoce. A ausência de apoio parental pode potencializar esses problemas e prospectar complicações no desenvolvimento e crescimento saudável da criança.

A ausência paterna, inerente as questões de trabalho e à necessidade da informalidade laboral, compromete a participação do pai nesta prática. Estudo de Bueno e Viera (2014) revela que, diante da ausência da figura paterna geralmente se elege um substituto e, quando isso não ocorre, é possível que a mãe ocupe esse espaço significativo na vida dos filhos. $\mathrm{O}$ tipo de trabalho exercido pelo homem é considerado uma variável importante e que pode interferir no comportamento paterno. Neste sentido, a constituição brasileira prevê licença paternidade de apenas 5 dias podendo ser estendida para 20 dias para empresa públicas e privadas que aderiram ao Programa Empresa Cidadã (BRASIL, 1988, 2008) o que dificulta a incorporação e inserção paterna no processo de amamentação e cuidado com o recémnascido.

Contudo, convergindo com os achados do presente estudo, investigadores afirmam ser possível constatar o reconhecimento dos pais quanto a relevância de seu papel no apoio e incentivo às puérperas durante o AM. Além disso, percebem que esse envolvimento pode contribuir de forma positiva para a saúde da criança e para prevenção de potenciais complicações (TESTON et al., 2018). Para tal, é importante que no momento da amamentação seja promovido um ambiente acolhedor e tranquilo para o binômio mãe/bebê, a fim de que a fisiologia neuroendócrina da amamentação seja estabelecida (BRASIL 2015). A unicidade de cada pai e as estratégias encontradas em contribuir no processo nutricional do filho e fortalecimento dos vínculos familiares são notáveis na investigação. Nesta perspectiva, Strapasson et al., (2017) afirmam que o envolvimento do pai possibilita a construção do vínculo, estimulando sua responsabilidade na atenção ao cuidado familiar. As experiências que esses processos desencadeiam são distintos para cada um, favorecendo a tríade mãe-pai-bebê. 
A chegada de um novo membro na família traz à parentalidade a exigência da mudança de papéis sociais, a capacidade de prover, oferecer apoio, contribuir nos cuidados e fortalecer esta relação familiar (BRASIL, 2013). Entretanto, os achados apontam que, mesmo diante da compreensão dos pais sobre a necessidade de participar no processo do cuidado com os filhos, alguns demonstraram-se intimidados frente as novas funções sociais. Estudo conduzido por Martins (2018) mostra que ao longo da história a sociedade se organizou atribuindo papeis aos indivíduos condicionados por questões de gênero, reservando ao homem o papel de provedor, não cabendo-lhe desempenhar funções de cuidado e afeto com os filhos. Afirma também que atualmente esse espaço começa a se transformar em novas perspectivas paternas com vistas a ressignificação de suas atribuições.

No entanto, teorias impostas pela sociedade fazem com que a mulher reproduza posicionamentos patriarcais, reforçando que os cuidados e a nutrição dos filhos devem ser realizados pelas mães. Entretanto, investigação realizada por Ogaki e Sei (2015) mostra que a mulher tem forte influência na participação paterna nos diferentes pontos de inserção do cuidado, a qual só é processada quando a mãe oportuniza esse lugar ao homem.

A ideia de que o gênero feminino tem responsabilidade plena sobre os cuidados, educação, amamentação e serviços domésticos, ainda carrega marcas significativas que interferem no desmanche desses mitos impostos pela coletividade. Experienciar novas formas de paternidade provoca um impacto entre os desejos do pai e valores sociais, num contraponto que também põe em questão o modelo de masculinidade. Para tanto se entende que a construção do pai pós-moderno requer a participação de uma mãe sensível às necessidades do seu companheiro e eficiente no estímulo de sua participação no cuidado dos filhos e nas tarefas do cotidiano (FERREIRA et al., 2015). O estudo em questão aponta para a necessidade de maior enfoque nas orientações e incentivo da participação paterna na construção desta relação com a prática da amamentação. As informações prestadas aos pais desde o pré-natal e acompanhadas durante o puerpério contribuem para o fortalecimento familiar e para que a mulher compreenda que o pai não é apenas um incentivador da prática do aleitamento, mas o seu principal influenciador.

Convergindo com estas afirmativas, Jeneral et al., (2015) reforçam a necessidade de implementar estratégias de educação em saúde que contemplem além da mulher, sua parceria sexual, constituindo assim momento importante para incentivo e promoção da 
amamentação de forma exclusiva. Para Lima, Cazola e Picoli (2017), a participação dos profissionais responsáveis pelo pré-natal é fundamental nesse processo de orientação e inclusão paterna no cuidado e nutrição de seus filhos.

\section{CONSIDERAÇÕES FINAIS}

O estudo possibilitou constatar que os pais são conhecedores dos valores biológicos e psicológicos compreendidos na prática do AM para o desenvolvimento e crescimento saudáveis de seus filhos.

O envolvimento paterno, neste processo, mobiliza diferentes significados e sentimentos aos homens e se apresenta de maneira distinta a cada pai que vive a experiência. A maioria dos pais consegue compreender a importância da sua inserção na nutrição de seus filhos e se percebem como ativos neste processo, mesmo que contribuindo com as tarefas domésticas diárias.

No entanto, o estudo identifica inúmeras dificuldades quanto ao papel paterno na amamentação relacionada à influência social e cultural, às questões de gênero e de demandas inerentes ao cotidiano da vida, o que permite dizer que a relação entre paternidade e amamentação se encontra em constante construção.

As limitações do estudo concentram-se na abordagem qualitativa do estudo não sendo possível generalizar os achados.

Acredita-se que este estudo possa contribuir no avanço das discussões e problematizações quanto à inserção e participação ativa do homem nos processos de cuidado e nutrição dos seus filhos.

Sugere-se que políticas públicas e programas de incentivo, apoio e defesa da inserção paterna neste contexto sejam implementadas.

Novos estudos com abordagens direcionadas à inserção paterna no cuidado e nutrição dos lactentes são necessários para potencializar e sensibilizar a parceria do homem em espaços do cotidiano da vida familiar. 


\section{REFERÊNCIAS}

ANDRADE, B.C.P. et al. rooo Dias: uma janela de oportunidades. Revista Uningá Review, Maringá, v. 25, n. 2, p. 91-93, fev. 2016. Disponível em: http://34.233.57.254/index.php/uningareviews/article/view/1754/136o.

BRASIL. Emenda Constitucional n 20, is de dezembro de 1988. Disponível em < http://www.planalto.gov.br/ccivil_03/Constituicao/Emendas/Emc/emc2o.htm>

BRASIL. Lei no 11.770 , de 9 de setembro de 2008. Cria o programa Empresa Cidadã, destinada a prorrogação de licença-maternidade mediante concessão de incentivo fiscal, e altera a Lei no 8.212, de 24 de julho de i991. Disponível em: 〈http://www.planalto.gov.br/ccivil_03/_ato2007-2010/2008/lei/lir77o.htm〉.

BRASIL. Ministério da Saúde. Resolução no 466, de 12 de dezembro de 2012. Diretrizes e normas regulamentadoras de pesquisas envolvendo seres humanos. Brasília, DF: Ministério da Saúde, 12 dez. 2012. Disponível em: 〈http://conselho.saude.gov.br/resolucoes/2012/Reso466.pdf 〉.

BRASIL. Ministério da Saúde. Secretaria de Atenção à Saúde. Departamento de Ações Programáticas e Estratégicas. Atenção humanizada ao recém-nascido de baixo peso: método canguru: manual técnico. 2. ed. Brasília, DF: Ministério da Saúde, 2013. Disponível em: http://bvsms.saude.gov.br/bvs/publicacoes/atencao_humanizada_recem_nascido_canguru .pdf.

BRASIL. Ministério da Saúde. Secretaria de Atenção à Saúde. Departamento de Atenção Básica. Saúde da criança: aleitamento materno e alimentação complementar. 2. ed. Brasília, DF: Ministério da Saúde, 2015. Disponível em: http://bvsms.saude.gov.br/bvs/publicacoes/saude_crianca_aleitamento_materno_cab23.pd f.

BUENO, R. K.; VIEIRA, M. L. Análise de estudos brasileiros sobre o pai e o desenvolvimento infantil. Psicol. Argum., Curitiba, v. 32, n. 76, p. 151-159, jan./mar 2014. Disponível em: https://periodicos.pucpr.br/index.php/psicologiaargumento/article/view/20247/19529. DRAGO, A. B.; MENANDRO, M. C. S. A paternidade e a maternidade sob o olhar de jovens de classe média e baixa: Um estudo em representações sociais. Rev. Colomb. Psicol., 
Bogotá, v. 23, n. 2, p. 311-324, jul./dic. 2014. Disponível em: 〈https://dialnet.unirioja.es/servlet/articulo?código=5016331.

FERREIRA, F. H. et al. Experiência paterna no primeiro ano de vida da criança: revisão integrativa de pesquisas qualitativas. Rev. Eletrônica Enferm., Goiânia, v. 17, n. 3, jul. 2015. Disponível: https://www.fen.ufg.br/revista/vi7/n3/pdf/vi7n3a21.pdf.

GASKELL, G. Entrevistas individuais e de grupos. In: BAUER, M. W.; GASKELL, G. (org.). Pesquisa qualitativa com texto, imagem e som: um manual prático. Petrópolis: Vozes, 2013. p. 64-89.

JENERAL, R. B. R et al. Aleitamento materno: uma reflexão sobre o papel do pai. Rev. Fac. Ciênc. Méd. Sorocaba, Sorocaba, v. 17, n. 3, p. I40-I47, 2015. Disponível em: https://revistas.pucsp.br/RFCMS/article/view/21445/pdf.

LIMA, J. P.; CAZOLA, L. H. O.; PICOLI, R. P. A participação do pai no processo de amamentação. Cogitare Enferm., Curitiba, v. 22, n. I, p. oI-07, jan./mar. 2017. Disponível em: https://revistas.ufpr.br/cogitare/article/view/47846/pdf.

MARANHÃO, T. A. et al. Fatores associados ao aleitamento materno exclusivo entre mães adolescentes. Cad. Saúde Colet., Rio de Janeiro, v. 23, n. 2, p. 132-139, 2015. Disponível em: http://www.scielo.br/pdf/cadsc/v23n2/1414-462X-cadsc-23-2-132.pdf.

MARTINS, L. H. C. Ser homem e ser pai: uma abordagem à luz da nova lei da guarda compartilhada. 2018. Dissertação (Mestrado Acadêmico em Sociologia) - Programa de PósGraduação em Sociologia, Universidade Estadual do Ceará, Fortaleza, 2018. Disponível em: http://siduece.uece.br/siduece/trabalhoAcademicoPublico.jsf?id=82742.

MINAYO, M. C. S. O desafio do conhecimento: pesquisa qualitativa em saúde. I4. ed. São Paulo: Hucitec, 2014.

OGAKI, H. A.; SEI, M. B. A função paterna na clínica infantil. Estilos Clin., São Paulo, v. 20, n. 2, p. 296-309, ago. 2015. Disponível em: http://pepsic.bvsalud.org/pdf/estic/v2on2/aogv2on2.pdf

OLIVEIRA, A. E. M.; LIMA, P. P. Benefícios da amamentação para a nutriz e o lactente. 2015. Monografia (Bacharelado em Enfermagem) - Universidade São Francisco, Bragança Paulista, 2015. Disponível em: http://lyceumonline.usf.edu.br/salavirtual/documentos/2675.pdf. 
RÊGO, R. M. V. et al. Paternidade e amamentação: mediação da enfermeira. Acta Paul. Enferm., São Paulo, v. 29, n. 4, p. 374-380, 2016. Disponível em: http://www.scielo.br/pdf/ape/v29n4/1982-0194-ape-29-04-0374.pdf.

SETÚBAL, J. L. Benefícios da amamentação para a mãe. SBP Amamentação: novo formato, Rio de Janeiro, n. 23, ago. 2017. Disponível em: https://www.sbp.com.br/treinamento/hotsites/sbp-amamentacao/artigos-sobrealeitamento-materno/

STRAPASSON, M. R. et al. Percepção do pai acerca da paternidade no alojamento conjunto. Rev. Enferm. UFSM, Santa Maria, v. 7, n. I, p. 8o-89, jun. 2017. Disponível em: https://periodicos.ufsm.br/reufsm/article/view/22295.

TESTON, E. F. et al. Aleitamento materno: percepção do pai sobre seu papel. Rev. Enferm. Cent.-Oeste Min., Divinópolis, v. 8, art. e2723, 2018. Disponível em: http://seer.ufsj.edu.br/index.php/recom/article/download/2723/2042.

VICTORA, C. G. et al. Amamentação no século 21: epidemiologia, mecanismos, e efeitos ao longo da vida. Epidemiol. Serv. Saúde, Brasília, DF, v. 25, n. I, p. I-24, 2016. Disponível em: http://scielo.iec.gov.br/pdf/ess/v25nI/Amamentacaor.pdf.

VICTORA, C. G. et al. Association between breastfeeding and intelligence, educational attainment, and income at 30 years of age: a prospective birth cohort study from Brazil. Lancet, London, v. 3, n. 4, p. e199-e205, Apr. 2015. Disponível em: https://www.thelancet.com/journals/langlo/article/PIIS2214-Io9X(I5)700o2I/fulltext\#articleInformation

WABA WORLD BREEDFEEDING SEMANA. Disponível em: https://worldbreastfeedingweek.org/2019/press-release/. WALLENBORN, J. T.; CHAMBERS, G. J.; MASHO, S. W. The role of paternity acknowledgment in breastfeeding non initiation. J. Hum. Lact., Thousand Oaks, CA, v. 34, n. 4, p. 737-744, Nov. 2018. Disponível em: https://journals.sagepub.com/doi/abs/ıo.1177/o890334417743209? journalCode=jhla. 